\section{UNA VISIÓN PROPOSITIVA PARA LA EXPANSIÓN DEL DERECHO PROCESAL CONVENCIONAL DE LOS DERECHOS HUMANOS}

Alfonso Jaime Martínez Lazcano** Jaime Alfonso Cubides Cárdenas":

\section{RESUMEN}

Desde la óptica del dinamismo del procesalismo científico, que se empezó a gestar en el desplazamiento del derecho procesal del campo

$$
\text { Recibido: abril } 13 \text { de } 2015 \text { - Aceptado: junio } 04 \text { de } 2015
$$

" El artículo es inédito en cuanto es una versión original preparada para la Revista del Instituto Colombiano de Derecho Procesal y expone resultados del proyecto de investigación: "Recepción de estándares internacionales de protección aplicables a un proceso penal que investigue la comisión de graves crímenes internacionales, por parte del ordenamiento investigue la comisión de graves crímenes internacionales, por parte del ordenamiento
jurídico colombiano", que forma parte de la línea de investigación "Fundamentación e jurídico colombiano", que forma parte de la línea de investigación "Fundamentación e implementación de los derechos humanos", del Grupo de Investigación Persona, Instituciones y Exigencias de Justicia, registrado con el código COL0120899 en Colciencias, vinculado al Centro de Investigaciones Sociojurídicas (Cisjuc),

** Abogado, doctor en Derecho Público, profesor de la Universidad Autónoma de Chiapas y Abogado, doctor en Derecho Público, profesor de la Universidad Autónoma de Chiapas la Universidad del Sur y profesor honorario de la Facultad de Derecho de la Universidad Nacional Autónoma de México (UNAM). Director de la Revista Jurídica Primera Instancia y presidente del Colegio de Abogados Procesalistas Latinoamericanos. Miembro del Instituto Iberoamericano de Derecho Procesal, de la Asociación Mundial de Justicia Constitucional, de la Asociación Panameña de Derecho Procesal Constitucional, de la Asociación Colombiana de Derecho Procesal Constitucional y de la Asociación Paraguaya de Derecho Procesal Constitucional.

** Abogado de la Universidad Autónoma de Colombia, especialista en Derecho Público de la misma casa de estudios, especialista y magíster en Docencia e Investigación con énfasi en Ciencias Jurídicas, de la Universidad Sergio Arboleda, maestrante en Derecho Administrativo de la misma Universidad y doctorando en Derecho en la línea de investigación de Derecho Constitucional, de la Universidad de Buenos Aires. Docente investigador y líder del Grupo de Investigación Persona, Instituciones y Exigencias de Justicia, de la Universidad Católica de Colombia.

ISSN 2346 - 3473 • pp. 167-197 • Julio - Diciembre de 2015 • Bogotá, D.C. - Colombia 167

ALFONSO JAIME MARTINEZZ LAZCANO Y JAIME ALFONSO CUBIDES CÁRDENAS

constitutional procedural Right and its relationship with the constitutional paradigm. The third explains the convergence of substantive constitutional law and substantive conventional law and the use of the block of constitutionality. Finally, examines the conventional division of substantive right and conventional procedural right, the asserting of its autonomy and the universalization from the regional protection systems. It concludes by determining the elements, factors and characteristics that enable legal systems within the treatment, study and deepening of this new concept which allows the incorporation of international standards in pursuit of material and effective protection of human rights.

Keywords: constitutional procedural law, human rights, conventional procedural law, inter-American system.

\section{INTRODUCCIÓN.}

El derecho es un producto cultural, una creación lingüística, conformado con base en la evolución de las relaciones humanas y en las formas cómo aprovechamos nuestro entorno; estas, cada vez más complejas, estimulan el surgimiento de nuevas especialidades jurídicas sustantivas y procesales. En México, por ejemplo, la Constitución de 1917 estableció por primera vez derechos sociales para regular las relaciones laborales y de las actividades del hombre del campo, posteriormente, emerge el derecho administrativo y así consecutivamente.

En el siglo XX y a principios del XXI, se constituye una categoría independiente: el Derecho Procesal Constitucional ${ }^{2}$. Sin embargo, este absorbe a otra disciplina todavía más novel denominada como un segmento de esta, el Derecho Procesal Constitucional Trasnacional.

Hoy, el impacto en los regímenes nacionales de los sistemas de protección regional de derechos humanos implica su estudio de forma autónoma para su mayor comprensión, lo que envuelve la división entre el derecho procesal

\footnotetext{
Al respecto, se puede consultar a FERRER MAC-GREGOR, Eduardo. "La ciencia del derecho procesal constitucional” En: Díkaion. Año 22, núm. 17. 2008. p. 98; donde se expone: "La finalidad del presente estudio consiste en ubicar el periodo fundacional del expone: "La finalidad del presente estudio consiste en ubicar el periodo fundacional del
Derecho Procesal Constitucional como nueva disciplina científica. El autor parte de la Derecho Procesal Constitucional como nueva disciplina científica. El autor parte de la manera en que surgen las diversas disciplinas del Derecho Procesal y del Derecho Constitucional, anbas como fruto del decho publico alemán del siglo XIX. De ahi analiza las cuatro etapas de con años de 1928 y 1956, a la luz del procesalismocientico de la época y de las ensenanzas de Kelsen, Couture, Alcala-Zamora, Calamandrei, Cappelletti y Fix-Zamudio." Para ampliar ver: FERRER MAC-GREGOR, Eduardo. Panorámica del Derecho Procesal Constitucional $y$ Convencional. Madrid: Editorial Marcial Pons, 2013.
}

del derecho privado al derecho público'y la separación de la acción y la pretensión, se hace necesario el estudio de nuevas tendencias. La visión que hoy se propone es el Derecho Procesal Convencional de los derechos humanos para su aplicabilidad y efectividad dentro de los ordenamientos jurídicos internos, esto a partir de un método deductivo con un enfoque descriptivo, crítico-analítico y propositivo. La exposición se desarrollará en cuatro ejes temáticos, el primero aborda una conceptualización del Derecho Procesal Convencional de los Derechos Humanos, la incorporación del corpus iuris latinoamericano y la recepción nacional de los Derechos Humanos sustantivos convencionales. El segundo presenta la discusión en torno a la existencia del Derecho procesal constitucional transnaciona y su relación con el paradigma constitucional. El tercero explica la convergencia entre el derecho constitucional sustantivo y el Derecho convencional sustantivo y la utilización del bloque de constitucionalidad. Por último, se examina la división del Derecho sustantivo convencional y el Derecho procesal convencional, la afirmación de su autonomía y la universalización a partir de los sistemas regionales de protección. Como conclusión se determinan los elementos, factores y rasgos característicos que posibilitan dentro de los sistemas jurídicos el tratamiento, estudio y profundización de esta nueva concepción que viabiliza la incorporación de estándares internacionales en búsqueda de la protección material y efectiva de los derechos humanos.

Palabras clave: Derecho procesal constitucional, derechos humanos, Derecho procesal convencional, sistema interamericano.

\section{Abstract}

From the standpoint of the scientific procedural dynamism, which began to gestate in the displacement of procedural law in the field of private law to public law and the separation between action and pretense, the study of new trends becomes necessary. The vision proposed today is the Conventional Procedural Law of human rights for its applicability and effectiveness within internal legal systems, this from a deductive method with a descriptive approach, critical-analytical and purposeful. The exposition will be develop in four themes, the first board a conceptualization of Conventional Procedural Law of Human Rights, the incorporation of Latin American corpus iuris and the national reception of conventional substantive Human Rights. The second presents the discussion around the existence of transnational

SAÍD, Alberto y GONZÁLEZ GUTIÉRREZ, Isidro M., Teoría General del Proceso. México: IURE editores, 2006 p. 100.

168

Revista del Instituto Colombiano de Derecho Procesal • No. 42

convencional sustantivo y el derecho convencional procesal de los derechos humanos. El maestro Fix Zamudio, con la claridad que le caracteriza, explic el fenómeno académico de catalogar: "las divisiones que se han hecho de las ramas del Derecho, no pueden considerarse como sectores estancos, sino clasificaciones doctrinales para poder profundizar ciertas instituciones jurídicas, pues, en última instancia, el Derecho es una unidad, pero tan extensa, que salvo el examen de la teoría general o desde punto de vista filosófico, es preciso dividirla cuando se trata de sectores del derecho positivo, para estar en aptitud de profundizar su análisis"

En forma similar, nos comenta el destacado profesor argentino Omar Erinzonce: "Tal como se expresa en la clásica enseñanza de Calamandrei, las formas procesales no sirven, como podrían pensar los profanos, para hacer más complicado y menos comprensible el desarrollo del proceso, sino por el contrario, para hacerlo más simple y claro"4.

El carácter dinámico del Derecho Procesal hace que su evolución se vea marcada por varias propuestas que buscan irradiar nuevos escenarios; por ejemplo, los fenómenos de la internacionalización del Derecho ${ }^{5}$ y la constitucionalización del Derecho ${ }^{6}$ hacen repensar a la comunidad jurídica acerca de las relaciones que se reconocían tradicionalmente como unidimensionales y que pasaron a ser concepciones sistemáticas o complejas. Es por esto que la relevancia de la propuesta se centra en el análisis de diferentes paradigmas, que se consolidaban como estáticos o pétreos, que no pueden ser concebidos desde un punto de vista irrefutable cuando podemos observar que cada vez más van ganando campo dentro de las ciencias jurídicas. La concepción legalista que entroniza a la ley ha sido sustituida por un pensamiento constitucionalista; no obstante, concebir hoy un sistema jurídico sin la mención a los derechos humanos y a los tribunales regionales de protección, se consideraría obsoleto.

FIX ZAMUDIO, Héctor, "El Derecho Procesal Constitucional como un sector de a defensa de la Constitución", Estudios de Derecho Procesal Constitucional. Tomo Bogotá: Editores Ltda., 2011. p. 165

BERINZONCE, Roberto Omar. "El principio de legalidad formal bajo el prisma de la Constitución normatizada". Revista del Instituto Colombiano de Derecho Procesal. Bogotá: Edición virtual número 40, 2014. p. 66.

Véase: AGUILAR, Gonzalo. "La internacionalización del Derecho Constitucional. Estudios Constitucionales. Año 5. Vol. 1. 2007. Talca. Universidad de Talca, pp. 223-281.

Consultar a: GUASTINI, Ricardo. La "constitucionalización" del ordenamiento jurídico: el caso italiano. Estudios de Teoría Constitucional". Primera edición. México: UNAM, IIJ. 2001 pp. 1-273. CUBIDES, Jaime "La relación del fenómeno de la constitucionalización del derecho con el derecho procesal constitucional". Revista Justicia Juris. Vol. 8. № 1 Bogotá: Universidad Autónoma del Caribe, 2012. pp. 22-29. 
Solo basta reflexionar acerca de la inclusión o posibilidad de activar sistemas supranacionales dentro de la sociedad, para determinar si los ordenamientos jurídicos se ajustan a estándares internacionales para la protección de derechos humanos.

\section{CONCEPTUALIZACIÓN DEL DERECHO PROCESAL CONVENCIONAL DE LOS DERECHOS HUMANOS.}

El Derecho Procesal Convencional de los derechos humanos no es una subcategoría del Derecho Procesal Constitucional. Existen hoy dos planos diferentes y convergentes de protección jurisdiccional de derechos humanos: el ámbito nacional tradicional y el internacional. Como dice Ayala Corao: "La persona humana como sujeto de derechos fundamentales está hoy en día doblemente protegida por el derecho constitucional democrático y por el derecho internacional; es decir, por el derecho constitucional de los derechos humanos y por el derecho internacional de los derechos humanos"

Al momento de determinar si hay una efectiva garantía de los derechos humanos ${ }^{8} y$, en especial, que puedan ser disfrutados plenamente por sus titulares surgen cuestionamientos sobre tal efectividad en los Estados, más aún al tener en cuenta los numerosos procesos que se tienen a disposición para tal salvaguarda, pues, sin contar la amplitud tanto de forma como de contenido de dichos procesos, la protección de esos derechos se ha visto infructuosa9. Es en ese contexto donde surge el derecho procesal convencional de los derechos humanos como respuesta, al ser un medio de garantía jurisdiccional de carácter

AYALA CORAO, Carlos M, "Recepción de la jurisprudencia internacional sobre los derechos humanos por la jurisprudencia constitucional". Derecho procesal constitucional. México: Porrúa. pp. 1471-1472

En este aspecto tenemos que recordar "que si queremos lograr una cultura eficiente de reconocimiento, fomento y garantía de los derechos humanos, entonces debemos simplificar el camino hacia ello ¿cómo? Evitando clasificaciones técnicas que a nada práctico conduzcan" CARPIZO, Enrique "El control de convencionalidad y su relación con el sistema con con humanos". Boletín Mexicano de Derecho Comparado. 138. México: UNAM, 2013. p. 959.

$9 \quad$ Así, "la responsabilidad estatal no termina cuando las autoridades competentes emiten una decisión o una sentencia; se requiere, además, que el Estado garantice los medios para ejecutar dichas decisiones definitivas. Y la efectividad de las sentencias depende de su ejecución: el proceso debe tender a la materialización de la protección del derecho reconocido en el pronunciamiento judicial mediante la aplicación idónea de dicho pronunciamiento". D'EMPEIRE, Eduardo Alfredo, "Las garantías judiciales: un análisi de estándares fijados por la Corte Interamericana de Derechos Humanos". Diálogos de Saber, 38. Bogotá, 2013. p. 162

ISSN 2346 - 3473 • pp. 167-197 • Julio - Diciembre de 2015 • Bogotá, D.C. - Colombia 171

ALFONSO JAIME MARTíNEZ LAZCANO Y JAIME ALFONSO CUBIDES CÁRDENAS

Interamericano de Derechos Humanos"13. Este sistema brinda a cada uno de sus integrantes insumos teóricos que no solo dan contenido a los derechos humanos protegidos, además, ofrece mecanismos para su tutela ${ }^{14}$, asimismo, se nutre ampliamente de la producción dogmatica de sus dos grandes órganos: la Comisión Interamericana de Derechos Humanos (más adelante Comisión IDH o CIDH) y la Corte Interamericana de Derechos Humanos (posteriormente Corte IDH), las cuales ayudan ampliamente en esta tarea.

El artículo 23 del Reglamento de la Comisión IDH dispone que:

"las quejas o denuncias deben fundarse en los derechos previstos por la Declaración Americana de los Derechos y Deberes del Hombre, la Convención Americana sobre Derechos Humanos "Pacto de San José de Costa Rica", el Protocolo Adicional a la Convención Americana sobre Derechos Humanos en Materia de Derechos Económicos, Sociales y Culturales "Protocolo de San Salvador", el Protocolo a la Convención Americana sobre Derechos Humanos Relativo a la Abolición de la Pena de Muerte, la Convención Interamericana para Prevenir y Sancionar la Tortura, la Convención Interamericana sobre Desaparición Forzada de Personas y la Convención Interamericana para Prevenir, Sancionar y Erradicar la Violencia contra la Mujer "Convención de Belém do Pará", conforme a sus respectivas disposiciones, el Estatuto de la CIDH y su Reglamento".

La Corte IDH ha definido como instrumentos ${ }^{15}$

- Convención sobre la nacionalidad de la mujer (1933);

- Convención sobre asilo político (1935);

- Convención Interamericana sobre Concesión de los Derechos Civiles a la Mujer (1948);

Caso Ríos y otros Vs. Venezuela. Excepciones Preliminares, Fondo, Reparaciones y Costas. Sentencia de 28 de enero de 2009. Serie C No. 194, Párrafo 277.

13 MARTÍNEZ LAZCANO, Alfonso Jaime. "Sistema Latinoamericano de Protección de Derechos Humanos". Sistemas regionales de protección de derechos humanos. Tuxtla Gutiérrez: Editorial Revista Jurídica Primera Instancia, 2012. p. 129.

14 De esta manera "los Estados parte del sistema interamericano de derechos humanos deben asumir como estándares mínimos en materia de derechos humanos aquellos consignados en los instrumentos internacionales, cuyos atributos y garantías de tales derechos, en algunos casos constituyen límites al ejercicio de la soberanía". NOGUEIRA ALCALÁ, Humberto, "los desafíos del control de convencionalidad del corpus iuris interamericano para las jurisdicciones nacionales". Boletín Mexicano de Derecho Comparado, 135. México: UNAM, 2012. p. 1218

15 http://www.corteidh.or.cr [Consultado el 9 de abril de 2014] internacional constituido con base en sistemas regionales para tutelar derechos sustantivos previstos en tratados, convenios, protocolos, entre otros.

Néstor Pedro Sagües hace distinción más claramente en el ámbito procesal: "nos encontramos en la frontera entre el derecho procesal constitucional (ocupado de afirmar la supremacía constitucional nacional) y el derecho procesal transnacional, que atiende entre otros menesteres los procesos que diligencian ante la magistratura transnacional, incluyendo el de su ejecución en los ámbitos estatales domésticos"10.

Cuando los Estados fallan o violan derechos a sus habitantes, deben existir mecanismos jurisdiccionales internacionales facultados para velar y amparar a la persona. El fortalecimiento de los sistemas regionales de Derechos Humanos hace propicios nuevos debates, en los que no se deben establecer supremacía normativas, ya que entraríamos en disputas bizantinas, sino todo lo contrario, correlaciones más amplias que generen avances dentro de los sistemas normativos. La discusión acerca de si los sistemas regionales violan la soberanía nacional ${ }^{11}$ debe ser superada en pro de la protección efectiva de la persona, no podemos seguir utilizando el antiguo paradigma de la soberanía como una máxima absoluta infranqueable, en la que cualquier intromisión de órganos supranacionales se considere vulneración a la misma.

\subsection{INCORPORACIÓN DEL CORPUS IURIS LATINOAMERICANO.}

Por ejemplo, en la región de América los Estados parte han acordado lo que puede llamarse Corpus Iuris ${ }^{12}$ Latinoamericano, el cual está constituido por “(...) el conjunto de reglas, principios y directrices jurídicos que sustentan el Sistema

10 SAGÜES, Néstor Pedro. Derecho Procesal Constitucional logros y obstáculos. Lima: Centro de Estudios Constitucionales, 2008. p. 242 .

11 Ver más: TURÉGANO, Isabel. "Soberanía". Eunomía: Revista en Cultura de la Legalidad, №. 4. Madrid: Universidad Carlos III, 2013. pp. 154-162.

12 En las sentencias de la Corte IDH, se han utilizado los conceptos de corpus juris internacional y corpus iuris interamericano. Cfr. Corte IDH. Caso Goiburú y otros Vs. Paraguay. Fondo, Reparaciones y Costas. Sentencia de 22 de septiembre de 2006. Serie C No. 153, Párrafo 85; Corte IDH. Caso Gomes Lund y otros (Guerrilha do Araguaia) Vs. Brasil. Excepciones Preliminares, Fondo, Reparaciones y Costas. Sentencia de 24 de noviembre de 2010. Serie C No. 219, Párrafo 111; Corte IDH. Caso Anzualdo Castro Vs. Perú Excepción Preliminar, Fondo, Reparaciones y Costas. Sentencia de 22 de septiembre de 2009. Serie C No. 202, Párrafo 67; Corte IDH. Caso Forneron e hija Vs. Argentina. Fondo, Reparaciones y Costas. Sentencia de 27 de abril de 2012 Serie C No. 242, Párrafo 137; Corte IDH. Caso de los "Niños de la Calle" (Villagrán Morales y otros) Vs. Guatemala. Fondo. Sentencia de 19 de noviembre de 1999. Serie C No. 63, Párrafo 194; Corte IDH.

172 Revista del Instituto Colombiano de Derecho Procesal • No. 42

- Convención sobre asilo territorial (1954);

- Convención sobre asilo diplomático (1954);

- Convención Americana sobre Derechos Humanos (1969);

- Convención para prevenir y sancionar los actos de terrorismo configurados en delitos contra las personas y la extorsión conexa cuando estos tengan trascendencia internacional (1971);

- Estatuto de la Comisión Interamericana de Derechos Humanos (1979);

- Estatuto de la Corte Interamericana de Derechos Humanos (1979);

- Convenio de Sede entre el Gobierno de Costa Rica y la Corte Interamericana de Derechos Humanos (1981);

- Convención Interamericana para Prevenir y Sancionar la Tortura (1987);

- Convención Interamericana sobre conflictos de leyes en materia de adopción de menores (1988);

- Protocolo a la Convención Americana sobre Derechos Humanos relativo a la Abolición de la Pena de Muerte (1990);

- Carta de la Organización de los Estados Americanos (1993);

- Convención Interamericana sobre Desaparición Forzada de Personas (1994);

- Convención Interamericana sobre Restitución Internacional de Menores (1994);

- Convención Interamericana para Prevenir, Sancionar y Erradicar la Violencia contra la Mujer "Convención de Belem Do Para" (1995);

- Convención Interamericana sobre obligaciones alimentarias ámbito de aplicación (1996);

- Convención Interamericana contra la Corrupción (1997);

- Convención Interamericana sobre tráfico internacional de menores (1997);

- Reglamento de la Comisión Interamericana de mujeres (1998);

- Protocolo Adicional a la Convención Americana sobre Derechos Humanos en Materia de Derechos Económicos, Sociales y Culturales "Protocolo de San Salvador" (1999);

- Convención Interamericana para la Eliminación de todas las Formas de Discriminación contra las Personas con Discapacidad (1999),

- Declaración de Principios sobre la Libertad de Expresión (2000),

- Carta Democrática Interamericana (2001).

- Principios y Buenas Prácticas sobre la Protección de las Personas Privadas de Libertad en las Américas (2008);

- Estatuto de la Comisión Interamericana de Mujeres (2008);

174. Revista del Instituto Colombiano de Derecho Procesal • No. 42 
- Reglamento de la Comisión Interamericana de Derechos Humanos (2009); y

- Reglamento de la Corte Interamericana de Derechos Humanos (2010).

\subsection{RECEPCIÓN NACIONAL DE LOS DERECHOS HUMANOS SUSTANTIVOS.}

Los derechos humanos sustantivos son aquellos que tiene todo ser humano por el simple hecho de ser y representan el vínculo jurídico con el Estado y con los organismos internacionales. Estos tienen, correlativamente, una serie de obligaciones a través de sus agentes de no hacer o de hacer; de no interferir en la vida de las personas sin justificación razonable y promover e impulsar el desarrollo individual, colectivo y social; de resolver o prevenir conflictos que lesionen derechos humanos.

Los derechos sustantivos se escinden así, en contrapartida de los derechos procesales, sin dejar de afirmar la acción como un derecho humano que faculta el acceso a la justicia como derecho sustantivo. "El derecho sustantivo del Sistema Interamericano de Derechos Humanos tiene su basamento, esencialmente, en la Convención (...) el principal objetivo que persiguen los Estados Americanos signatarios (...) es consolidar un régimen de libertad personal y de justicia social, fundado en el respeto de los derechos esenciales del hombre. Asimismo, acordaron que la consecución de este propósito debía efectuarse dentro del cuadro de las instituciones democráticas de cada uno de los países firmantes" ${ }^{\prime 16}$.

El punto neurálgico dentro de los Estados no se centra en el reconocimiento legislativo de los derechos de las personas, se concentra en la polémica que conlleva la recepción nacional ${ }^{17}$ de los derechos humanos sustantivos y el alcance que pueden llegar a tener el reconocimiento de derechos ${ }^{18}$ que anteriormente no estaban dentro de la escena jurídica y que configuran nuevas tensiones dentro de diferentes poderes del Estado. Además, un derecho concebido desde la órbita internacional genera obligaciones para el Estado, que llevan inmersas nuevas

16 CARRASCO SOULÉ, Hugo. "El derecho sustantivo del Sistema Interamericano de derecho humanos". Temas Selectos del Sistema Interamericano de Protección de Derecho Humanos. Tuxtla Gutiérrez: Editorial Revista Jurídica Primera Instancia, 2012. pp. 5 y 8

17 Consultar un ejemplo en: AYALA, Carlos. "Recepción de la jurisprudencia internacional sobre Derechos Humanos por la jurisprudencia constitucional". Revista Urbe Et Ius. Vol. $1 \mathrm{~N}^{\circ} 11$. Lavalle. Asociación Civil Urbe et Ius, 2014. pp. 57-83.

${ }_{18}$ Al respecto ver: CUBIDES, Jaime. "Disertaciones sobre las parejas del mismo sexo a través del rol ejercido por la Corte Constitucional Colombiana en el reconocimiento de sus derechos". Anuario de Derecho. Año 28. № 28. 2011. Mérida: Universidad de los Andes. pp. 13-36. ISSN 2346 - 3473 • pp. 167-197 • Julio - Diciembre de 2015 • Bogotá, D.C. - Colombia 175

ALFONSO JAIME MARTÍNEZ LAZCANO Y JAIME ALFONSO CUBIDES CÁRDENAS

- Derecho a la propiedad privada.

- Derecho de circulación y de residencia.

- Derechos políticos.

- Igualdad ante la ley.

- Protección judicial.

- Derechos económicos, sociales y culturales.

- Desarrollo progresivo.

El derecho procesal en sí mismo es un derecho sustantivo que representa los requisitos necesarios para constituir un proceso, que se describe como el debido proceso.

Esta enunciación es solo para efectos pedagógicos descriptivos y no es un señalamiento expreso de un catálogo, a contrario sensu, se considera que su naturaleza es de textura abierta ${ }^{20}$ porque se pueden insertar nuevos derechos que no estén considerados dentro de esta lista, los sistemas jurídicos actuales deben reconocer su carácter dinámico, su maleabilidad y ductilidad, que serán necesarios en el acoplamiento a las nuevas discusiones dentro de las relaciones de los órdenes nacionales e internacionales ${ }^{21}$.

\subsection{EL ROL DE LA JURISPRUDENCIA DENTRO DE LA} CONSOLIDACIÓN DEL DERECHO PROCESAL CONVENCIONAL DE LOS DERECHOS HUMANOS.

También es fuente vinculante para los Estados la jurisprudencia consagrada en las sentencias, opiniones consultivas, medidas provisionales y supervisión de cumplimiento de sentencia que emite la Corte IDH. Cada sentencia de la Corte IDH genera una serie de jurisprudencias, que para el caso de México para que tengan el estatus de obligatorias debe reiterarse en varios casos el mismo sentido, además de la existencia de otros medios de creación como la resolución de contradicción de tesis y la modificación de razonamientos vinculantes.

"El primer nivel jurisprudencial está constituido por las sentencias o fallos de las Cortes, Tribunales, Salas Constitucionales o Cortes Supremas que se

Consultar a: MORA, Jorge. "El control de convencionalidad: un replanteamiento de principios y fuentes del Derecho". Revista Republicana. № 12. Bogotá: Corporación Universitaria Republicana. 2012. pp. 217-237.

${ }^{21} \quad$ Para ampliar en nuevas discusiones ver: GORDILLO PÉREZ, Luis Ignacio. "Hacia la consolidación de un constitucionalismo interordinamental". Anuario iberoamericano de justicia constitucional. $\mathrm{N}^{\circ}$. 18, 2014, pp. 275-328. responsabilidades para los agentes y operadores en el tratamiento de situaciones, en las que se presentan conflictos que anteriormente no se imaginaban. La no normativización del derecho no excluye la posibilidad de tutelar nuevos derechos que no se encuentran de forma expresa en la legislación nacional, pero que pueden ser reconocidos por autoridades, en especial por las jurisdiccionales ${ }^{19}$.

\subsection{Catálogo de derechos humanos sustantivo CONVENCIONALES.}

Los derechos que establecemos dentro del catálogo de derechos humanos sustantivos convencionales son:

- Derechos civiles y políticos.

- Derecho al reconocimiento de la personalidad jurídica.

- Derecho a la vida.

- Derecho a la integridad personal.

- Prohibición de la esclavitud y servidumbre.

- Derecho a la libertad personal.

- Garantías judiciales.

- Principio de legalidad y de retroactividad.

- Derecho a indemnización

- Protección de la honra y de la dignidad.

- Libertad de conciencia y de religión

- Libertad de pensamiento y de expresión.

- Derecho de rectificación o respuesta.

- Derecho de reunión.

- Libertad de asociación

- Protección a la familia.

- Derecho al nombre.

- Derechos del niño

- Derecho a la nacionalidad.

Al respecto ver: CORTE CONSTITUCIONAL. Sentencia T- 057 de 2015. La Corte Constitucional en este caso ampara el derecho fundamental "a que sea intentado" un tratamiento experimental a la paciente accionante denominado: "estimulación espin epidural para el tratamiento de estados de subconciencia (estado vegetativo-estado de conciencia mínimo) y programación de voltajes adecuados para el caso". Lo que la Doctrina norteamericana ha reconocido como el "Right to Try".

176

Revista del Instituto Colombiano de Derecho Procesal • No. 42

encuentran en el mismo plano o posición horizontal y las decisiones de los tribunales internacionales jerárquicamente superiores constituyen un sistema vertical frente a las primeras y son los encargados de integrar la interpretación de los instrumentos internacionales de protección de los derechos humanos" ${ }^{\prime 22}$

La jurisprudencia tiene no un rol secundario sino protagónico dentro de la consolidación del Derecho Procesal Convencional de los Derechos Humanos; su referencia, su utilización y su incidencia dentro de los Estados es cada vez más contundente, no podemos desconocer que el activismo judicial internacional y las soluciones transnacionales enmarcan una nueva etapa dentro del estudio del Derecho.

\section{DISCUSIÓN EN TORNO A LA EXISTENCIA DEL DERECHO PROCESAL CONSTITUCIONAL TRASNACIONAL.}

Existen destacados autores que se refieren al derecho procesal constitucional trasnacional ${ }^{23}$ cuando hablan del derecho procesal convencional de los derechos humanos como una especie del derecho procesal constitucional, sistematización en auge a finales del siglo XX y principios del XXI, con la idea de incluir todos los medios procesales instituidos para garantizar la supremacía constitucional. Pero el derecho procesal convencional no tiene únicamente ese propósito, debido a que es ajeno a este tipo de conflictos nacionales.

MORENO ALFONSO, René, “El valor de la jurisprudencia de los tribunales internacionales en el derecho local". Temas Selectos del Sistema Interamericano de Protección de Derechos Humanos. Tuxtla Gutiérrez: Editorial Revista Jurídica Primera Instancia, 2012. p. 337

23 VELANDIA CANOSA, Andrés, "Derecho procesal constitucional transnacional. El proceso ante la Corte Interamericana de Derechos Humanos", Neoprocesalismo, Universida Juárez Autónoma de Tabasco, Villahermosa, 2014, p. 400. GONZÁLEZ VALENZUELA, Alejandro. "El derecho procesal constitucional transnacional". En: Revista de la Facultad de Derecho, $\mathrm{N}^{\circ} 64,2009$, pp. 243-297. Coordinador: BAZÁN, Víctor. Derecho procesal constitucional americano y europeo. 2 tomos. Primera Edición, Editorial Abeledo Perrot, Buenos Aires, 2010, pp. 1836. COLOMBO CAMPBELL, Juan. La justicia constituciona Revista de Derecho (Valdivia) jul 2003, vol 14, 259-284. Seña el profesor Cacional "Devista de Derecho (

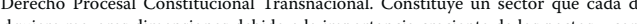
adquier mayes dios y conpromisos internacionales y de la creación de tribunales supranacionales, especialmente

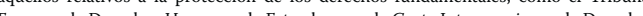
Europeo de Dech las Hus Humanos de San José, Costa Rica, que realzan una función semejante a la de los Tribu-
nales Constitucionales en el ámbito interno". 
La idea de integrar al derecho procesal constitucional transnacional al derecho procesal constitucional se debe al procesalista italiano Mauro Cappelletti, quien aglutinó en "tres sectores al derecho procesal constitucional: A) jurisdicción constitucional de libertad; B) jurisdicción constitucional orgánica; C) jurisdicción constitucional transnacional”24.

\subsection{CONTENIDO CONCEPTUAL DEL DERECHO PROCESAL CONSTITUCIONAL.}

La diversidad de medios jurisdiccionales o cuasi jurisdiccionales que adopten los países que tengan como intención anular los actos de cualquier autoridad que sean contrarios a los mandatos de la constitución o que provoquen una determinada conducta pública, cuyas motivaciones sean provocadas por el principio de supremacía constitucional, deben integrar el derecho procesal constitucional ${ }^{25}$

El maestro Héctor Fix-Zamudio realiza la siguiente clasificación del contendido del derecho procesal constitucional en México: "A) El juicio político de los altos funcionarios (art. 110); B) Las controversias constitucionales (art. 105, fracción I); C) La acción abstracta de inconstitucionalidad (art. 105, fracción II); D) El Procedimiento de investigación de la Suprema Corte de Justicia de la Nación (art. 97, párrafo II y III); E) El juicio de amparo (arts. 103 y 107); F) El juicio para la protección de los derechos político-electorales (art. 99, fracción v); G) El juicio de revisión constitucional electoral (art. 99, fracción iv); y H) Los organismos autónomos no jurisdiccionale protectores de los derecho humanos, inspirados en el modelo escandinavo del Ombudsman (art. 102, apartado B) ${ }^{26}$

Todos los casos tienen su fundamento en preceptos de la Constitución Federal.

\footnotetext{
FIX ZAMUDIO, Op. cit., p. 167.

25 Como el caso colombiano que establece una variedad de acciones de carácter constitucional que son tramitadas por autoridades distintas e incluso en algunos casos tiene desach le desarnol legislation y acción popular, la acción de grupo la acción de cumplimiento y la acción de inconstitucionalidad. Asimismo, establece como derechos fundamentales otros dos mecanismo de carácter constitucional que tienen un trámite especial ante la autoridad correspondiente como lo es el derecho de petición y el habeas corpus.

26 FIX ZAMUDIO, Héctor, "Breves reflexiones sobre el concepto y contenido del Derecho Procesal Constitucional". Derecho Procesal Constitucional. 4a ed. México: Porrúa, 2003. p. 299.
}

ISSN 2346 - 3473 • pp. 167-197 • Julio - Diciembre de 2015 • Bogotá, D.C. - Colombia

ALFONSO JAIME MARTÍNEZ LAZCANO Y JAIME ALFONSO CUBIDES CÁBDENAS

dicción constitucional ha evolucionado y ha incorporado figuras que no estaban presentes dentro de sus funciones originarias, o como ampliación de las mismas; como ejemplo podemos nombrar las sentencias interpretativas ${ }^{28}$ y lo que se ha denominado como el Estado de Cosas Inconstitucionales ${ }^{29}$.

Los tribunales constitucionales tienen distintas denominaciones y su acomodo dentro de la tradicional división de poderes ha sido también disímil en las naciones en las que se han constituido. Al respecto, el Dr. Eduardo Ferrer Mac-Gregor cataloga las formas en las que se han establecido estos tribunales en Latinoamérica:

a) sean como tribunales o cortes constitucionales autónomos ubicados fuer del aparato jurisdiccional ordinario (Chile, Ecuador, Guatemala y Perú); b) sean como tribunales o cortes autónomos dentro de la propia estructura del poder judicial (Bolivia y Colombia); c) sean como salas especializadas en materia constitucional pertenecientes a las propias cortes o tribunales supremos (El Salvador, Costa Rica, Nicaragua, Paraguay y Venezuela), d) o sean como cortes o tribunales supremos ordinarios realizando funciones de tribunal constitucional, aunque no de manera exclusiva (Argentina, Brasil, Honduras, México, Panamá y Uruguay $)^{30}$.

(1970-1973-1980-1989); Perú (1979 y 1993); El Salvador (1983-1991); Costa Rica (1989); Paraguay (1992); Colombia (1991); Bolivia (1994); Nicaragua (1995); Venezuela (1999); Brasil (1993); México (1995), y Ecuador (1996-1998).

28 Para ampliar ver: ESPINOSA SALDAÑA, Eloy. “Sentencias interpretativas: Sus alcances y algunas reflexiones sobre su uso a la luz de la experiencia peruana". Estudios Constitucionales. vol.4, núm. 2, 2006. pp. 203-220. Otro autor, además de la categoría de sentencias interpretativas, ha señalado las sentencias aditivas, al respecto Cfr. DÍAZ REVORIO, Francisco. "El control de constitucionalidad de las omisiones legislativas relativas en el derecho comparado europeo". Revista Española de Derecho ConstitucioAño 11, núm. 84, 2005. pp. 19-34.

Cfr. Las siguientes sentencias de la Corte Constitucional de Colombia donde se puede observar el uso de la figura jurídica del Estado de Cosas Inconstitucional: Sentencia SU-559 de 1997, Sentencias de revisión de tutela T-153 de 1998, T-606 de 1998, T-607 de 1998, T-847 de 2000 y T-966 de 2000, Sentencia T-590 de 1998, Sentencia T-068 de 1998,T-525 de 1997 y SU- 090 de 2008, Sentencia SU-250 de 1999 y Sentencia T-025 de 200

30 FERRER MAC-GREGOR, Eduardo. "Justicia Local Constitucional. La nueva sala constitucional en el estado de Veracruz", México: Ed., Fundación Universitaria de Derecho, Administración y Política SC, 2003. p.197.
DERECHO PROCESAL CONSTITUCIONAL

\begin{tabular}{|c|}
\hline Amparo \\
\hline Revisión constitucional electoral \\
\hline Juicio político de los altos funcionarios \\
\hline Protección de derechos político-electorales del ciudadano \\
\hline Acciones de incostitucionalidad (Federal y local) \\
\hline Controversias constitucionales (Federal y local) \\
\hline Acción por omisión legislativa (local) \\
\hline Cuestión de constitucionalidad (local) \\
\hline
\end{tabular}

2.2 LOS TRIBUNALES CONSTITUCIONALES DENTRO DEL DERECHO PROCESAL CONSTITUCIONAL.

El estudio del Derecho Procesal Constitucional se ha desarrollado con la fusión de dos parámetros de control, aquellos que tutelan derechos humanos o fundamentales de los particulares y el control de constitucionalidad de normas (leyes o actos del ejecutivo con fuerza de ley). Son los primeros los que se han nutrido de los derechos humanos sustantivos al constitucionalizarlos.

Los primeros tribunales constitucionales florecieron en Europa y después la idea se extendió a otros países ${ }^{27}$, actualmente, el concepto de justicia o juris-

Kelsen influyó en forma determinante en la creación de los primeros organismo jurisdiccionales especializados, establecidos por las cartas de Checoslovaquia y de la República Federal de Austria en 1920. Luego siguió en Italia (1948); República Federal de Alemania (1949); la antigua Yugoslavia (1953-1974); Chipre (1960); Grecia (1975) Portugal (1976-1982); España (1978); Bélgica (1980) Francia (1958); Turquía (1961 1982). Posteriormente, el proceso continuó en Europa del Este con la desintegración del mundo soviético; Polonia (1982-1986); Hungría (1989); Croacia (1990); Bulgaria (1991); Eslovenia (1991); Rumania (1991); Yugoslavia (1992); Estonia (1992); Albania (1992); República Checa (1992); Eslovaquia (1992); Macedonia (1992); Repúblicas Federativas Rusa (1993); Moldavia (1994); Bosnia-Herzegovina (1995) Ucrania (1996) y Letonia (1996). En forma progresiva se han introducido las instituciones de justicia constitucional en los países latinoamericanos: Ecuador (1948); Guatemala (1965-1985); Chile

$180 \quad$ Revista del Instituto Colombiano de Derecho Procesal • No. 42

\subsection{LA NATURALEZA DEL TRIBUNAL CONSTITUCIONAL ENTRE CONTROL E INTERPRETACIÓN.}

En este punto Ferrer Mac-Gregor menciona dos ópticas de la naturaleza de un tribunal constitucional, sea formal o materialmente, cuya función es conocer especial y exclusivamente de los conflictos constitucionales, sin incluir los tribunales convencionales de derechos humanos o la llamada justicia constitucional transnacional:

“a) Desde una perspectiva formal, que corresponde a la concepción tradicional, es aquel órgano creado para conocer especial y exclusivamente de lo conflictos constitucionales, situado fuera del aparato jurisdiccional ordinario e independiente tanto de este como de los poderes públicos. Conforme a esta concepción, las cortes o tribunales supremos pueden ser jurisdicciones constitucionales pero no son, en estricto sentido, tribunales constitucionales. Esta noción se identifica fundamentalmente con el modelo europeo de tribunal constitucional.

b) Una noción moderna y más amplia que corresponde a su enfoque material, entiende por tribunal constitucional al órgano jurisdiccional de mayo jerarquía que posee la función esencial o exclusiva de establecer la interpretación final de las disposiciones de carácter fundamental. En esta concepción se encuentran varias cortes o tribunales supremos de América Latina, donde podemos ubicar a la Suprema Corte de Justicia de México, que como veremos más adelante, debido a las reformas constitucionales de 1987, 1994 y 1999, se ha convertido materialmente en un tribunal constitucional" ${ }^{\text {31 }}$.

Los tribunales constitucionales deben ejercer su función de control constitucional de confrontación normativa entre la Constitución y normas de inferior jerarquía; aunado a lo anterior, deben realzar su función de intérpretes auténticos de la Constitución.

\section{Derechos humanos}

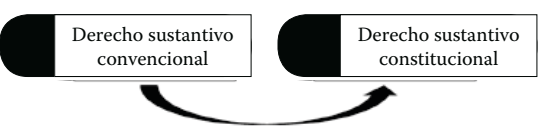

FERRER MAC-GREGOR, Eduardo, "Los tribunales constitucionales en Iberoamérica" México: FUNDA (Fundación Universitaria de Derecho, Administración y Política, S.C.) 2002. pp. 55-56.

182 Revista del Instituto Colombiano de Derecho Procesal • No. 42 
2.4 EL CONCEPTO DE CONSTITUCIÓN QUE RECABA DENTRO DEL PARADIgMA CONSTITUCIONAL

Constitución significa "(del latín constitutio-onis) forma o sistema de gobierno que tiene cada Estado; ley fundamental de la organización de un Estado ${ }^{32}$. Desde esta perspectiva podemos añadir que nace como una Carta Política para un Estado de derecho y con la evolución del derecho, además de ser una carta política, se convertiría en una norma jurídica para un Estado Social de Derecho, en palabras del profesor Velandia.

La Constitución es el conjunto de normas o principios de carácter nacional. Es el "acta de nacimiento de un Estado". En esta se establecen las normas más importantes y fundamentales de una nación sea en lo individual, grupo, colectivo o nacional. Es la carta política de organización interna de un país.

La Constitución posee ciertos atributos que le son propios y exclusivos; estos la distinguen de otro tipo de normas. Si bien es propio de toda ley mandar, disponer y regular, la constitución, como toda ley, lo hace, pero, por su naturaleza intrínseca, va más allá, constituye y funda. Este ir más allá que las restantes leyes hace que a ese conjunto de normas agrupadas en un texto se le dé el calificativo de ley suprema. Se trata, ciertamente, de una forma de ley; no obstante, goza de notas que la distinguen y sitúan en una posición diferente y elevada $^{33}$.

La constitución se divide en dos partes esencialmente: la dogmática y la orgánica. En la primera se encuentran los derechos humanos y sus garantías y en la segunda, las facultades de los poderes públicos. Denótese que el paradigma constitucional reconoce la supremacía constitucional como una máxima irrefutable.

\subsection{DECONSTRUCCIÓN DEL PARAdigMA CONSTITUCIONAL}

\section{LA APARICIÓN DE CONSTITUCIONES INCONVENCIONALES}

No obstante lo anterior, se puede afirmar que el Derecho Procesal Convencional conlleva el reconocimiento de inconvencionalidades que se pueden presentar dentro de las constituciones, es decir, normas constitucionales que violen la convención, en el caso americano, el pacto de San José de Costa Rica.

Un caso que podría considerarse independiente, es el caso de La Última Tentación de Cristo contra Chile, en el cual la condena versa en esencia porque

32 BARRAGÁN BARRAGÁN, José, "Constitución", Diccionario Jurídico Mexicano tomo I, Instituto de Investigaciones jurídicas UNAM, 5ª ed. México: Porrúa, 1992, p. 658.

${ }^{33}$ ARTEAGA NAVA, Elisur, "Tratado de derecho constitucional", volumen 1. México: OXFORD, 2003. p. 2.

ISSN 2346 - 3473 • pp. 167-197 • Julio - Diciembre de 2015 • Bogotá, D.C. - Colombia

ALFONSO JAIME MARTÍNEZ LAZCANO Y JAIME ALFONSO CUBIDES CÁRDENAS

es necesario ordenar la modificación del contenido normativo que regula el artículo 13 de la Constitución Política de los Estados Unidos Mexicanos.

Sin gran discusión, inclusive para autores renuentes a la influencia pactada por los Estados en los instrumentos y prácticas que el derecho procesal convencional impone y que implican una jerarquía sobre toda jurisdicción nacional, interesante y aleccionador son los siguientes calificativos que utiliza Pedro Sagües al referirse a la experiencia latinoamericana, después de casi dos décadas de la vigencia de la convención $\mathrm{ADH}$ : "permiten realizar un interesante balance acerca del grado de sometimiento y de invasión de los tribunales nacionales, respecto de la Corte Interamericana de Derechos Humanos...es probable que los tribunales locales se sometan a regañadientes -ya que nos les cabe otro remedio- a lo que resuelva el tribunal supranacional en un caso concreto" ${ }^{35}$.

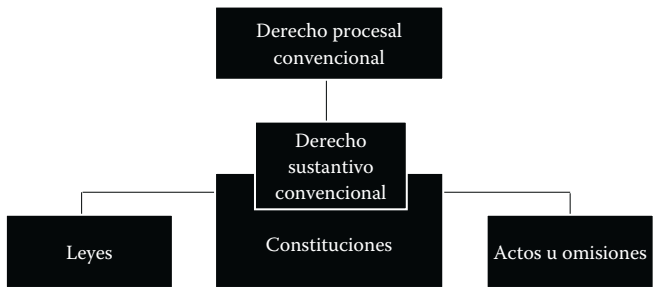

3. CONVERGENCIA ENTRE EL DERECHO CONSTITUCIONAL SUSTANTIVO Y EL DERECHO CONVENCIONAL SUSTANTIVO.

Los derechos humanos internacionales conforman el espacio (complementario) en el que converge el Derecho Constitucional Sustantivo y el Derecho Convencional Sustantivo.

En el momento en que los Estados se adhieren o aceptan a los convenios internacionales en materia de derechos humanos, se obligan a respetarlos, a garantizar su libre y pleno ejercicio a toda persona que esté sujeta a su jurisdicción, sin discriminación alguna por motivos de raza, color, sexo, idioma, religión, opiniones políticas o de cualquier otra índole, origen nacional o social, posición económica, nacimiento o cualquier otra condición social. Por tanto,

\section{SAGÜES. Op. cit. p. 242-245.}

ISSN 2346 - 3473 • pp. 167-197 • Julio - Diciembre de 2015 • Bogotá, D.C. - Colombia la Constitución Chilena contemplaba la previa censura. En los siguientes procesos contra México se puede palpar como la Corte IDH entra al estudio de la convencionalidad de la Constitución mexicana:

\subsubsection{Caso Radilla Pacheco.}

337. Los representantes solicitaron a este Tribunal que ordene al Estado realizar una reforma al artículo 13 constitucional, que regula el fuero de guerra, en virtud de que, "[a]unque en principio el artículo pareciera no generar problema alguno, las interpretaciones que de este se han hecho[,...] llevan a la necesidad de solicitar su reforma para alcanzar la precisión necesaria que impida que elementos del Ejército mexicano sean juzgados por tribunales militares cuando han cometido violaciones a los derechos humanos".

338. Para este Tribunal, no solo la supresión o expedición de las normas en el derecho interno garantizan los derechos contenidos en la Convención Americana, de conformidad a la obligación comprendida en el artículo $2^{\circ}$ de dicho instrumento. También se requiere el desarrollo de prácticas estatales conducentes a la observancia efectiva de los derechos y libertades consagrados en la misma. En consecuencia, la existencia de una norma no garantiza por sí misma que su aplicación sea adecuada. Es necesario que la aplicación de las normas o su interpretación, en tanto prácticas jurisdiccionales y manifestación del orden público estatal, se encuentren ajustadas al mismo fin que persigue el artículo $2^{\circ}$ de la Convención ${ }^{34}$. En términos prácticos, la interpretación del artículo 13 de la Constitución Política mexicana debe ser coherente con los principios convencionales y constitucionales de debido proceso y acceso a la justicia, contenidos en el artículo 8.1 de la Convención Americana y las normas pertinentes de la Constitución mexicana.

340. De tal manera, es necesario que las interpretaciones constitucionales y legislativas referidas a los criterios de competencia material y personal de la jurisdicción militar en México, se adecuen a los principios establecidos en la jurisprudencia de este Tribunal, los cuales han sido reiterados en el presente caso (supra párs. 272 a 277).

341. Bajo ese entendido, este Tribunal considera que no es necesario ordena la modificación del contenido normativo que regula el artículo 13 de la Constitución Política de los Estados Unidos Mexicanos.

2.4.2 Caso Cabrera Montiel.

234. Por otra parte, este Tribunal recuerda que ya consideró, en el Caso Radilla Pacheco, reiterado en los casos Fernández Ortega y Rosendo Cantú, que no

Cfr. Caso Castillo Petruzzi y otros Vs. Perú, supra nota 54, párr. 207; Caso Ximenes Lopes Vs. Brasil. Fondo, Reparaciones y Costas. Sentencia de 4 de julio de 2006. Serie C No. 149, párr. 83, y Caso Almonacid Arellano y otros Vs. Chile, supra nota 19, párr. 118.

184 Revista del Instituto Colombiano de Derecho Procesal • No. 42

estos pasan a formar parte del derecho positivo nacional, pero además, debido a su importancia, se incrustan o "aterrizan" a nivel constitucional.

De esta forma, la Constitución absorbe el Derecho Sustantivo Convencional de los Derechos Humanos.

En los Estados Unidos Mexicanos todas las personas gozarán de los derechos humanos reconocidos en esta Constitución y en los tratados internacionale de los que el Estado Mexicano sea parte, así como de las garantías para su protección, cuyo ejercicio no podrá restringirse ni suspenderse, salvo en los casos y bajo las condiciones que esta Constitución establece (A. 1, 1er. Párr.). Esta Constitución, las leyes del Congreso de la Unión que emanen de ella y todos los Tratados que estén de acuerdo con la misma, celebrados y que se celebren por el Presidente de la República, con aprobación del Senado, serán la ley suprema de toda la Unión (...) (A. 133.).

\subsection{UTILIZACIÓN DEL BLOQUE DE CONSTITUCIONALIDAD} DENTRO DEL DERECHO CONVENCIONAL.

Esta fusión del Derecho Convencional Sustantivo con el Derecho Procesal Sustantivo ha sido denominada bloque de constitucionalidad, al cual, sin embargo, otros autores han denominado a su vez bloque de convencionalidad ${ }^{36}$.

La existencia de un bloque de constitucionalidad implica identificar todas las normas (principios y reglas) y valores que, pese a no estar expresamente establecidas en la Constitución escrita, son materialmente constitucionales. Dentro de las normas y valores integrados a la CPEUM (por remisión expresa o tácita de esta), principalmente encontramos los estándares internacionales sobre derechos humanos ${ }^{37}$
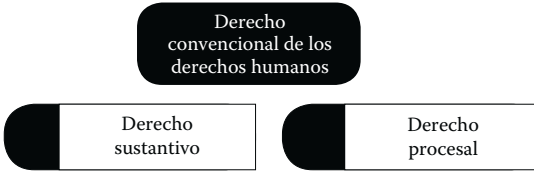

Al respecto ver: NOGUEIRA ALCALÁ, Humberto. "Los desafíos del control de conidad del corpus iuris interamericano para las jurisdicciones nacionales". Boletin Mexicano de Derecho Comparado. XLV, 2012. pp. 1167-1220. MIRANDA CAMARENA, Adrián Joaquín y NAVARRO RODRÍGUEZ Pedro. "El principio de interpretación conforme en el derecho constitucional mexicano" Opinión Jurídica. 13, 2014. pp. 69-79.

RODRÍGUEZ MANZO Graciela, et al, "Bloque de constitucionalidad en México". México: Suprema Corte de Justicia de la Nación. 2003. p.18.

186 Revista del Instituto Colombiano de Derecho Procesal • No. 42 


\section{DERECHO SUSTANTIVO CONVENCIONAL Y DERECHO} PROCESAL CONVENCIONAL.

Para comprender el fenómeno jurídico en su exacta dimensión debemos separar, como lo ha hecho el procesalismo científico, el Derecho Sustantivo Convencional del Derecho Procesal Convencional, ya que, como ha quedado expuesto, el primero es el que ha servido de fuente para enriquecer los derechos humanos sustantivos constituciones en su parte dogmática.

\subsection{Autonomía del DeRECHO PROCESAl CONVENCIONAL.}

Situación diferente es el Derecho Procesal Convencional de los Derechos Humanos que cuenta con su propia e independiente jurisdicción, doctrina y reglamentación procesal.

Es más, el contenido del derecho constitucional puede ser objeto de debate en el ámbito internacional, es decir, no es factible en forma lógica decir que existe el derecho procesal constitucional trasnacional, en el cual lo que se va juzgar, además de los actos u omisiones de los agentes del Estado parte, es todo el derecho interno, incluyendo las constituciones.

La importancia de su independencia procesal es necesaria y elemental si se quiere abordar de manera científica su rediseño.

Bien es cierto que en la génesis del Derecho Procesal Convencional y en general de todo este derecho, encontramos los mecanismos de aducción al Derecho Sustantivo Constitucional en sí y no al procesal. Y es que, una vez se ha producido la aceptación o adhesión al sistema regional, este se manifiesta en forma independiente del constitucional, repetimos, nos referimos al procesal, ya que el sustantivo se incrusta en las constituciones de forma inmediata.

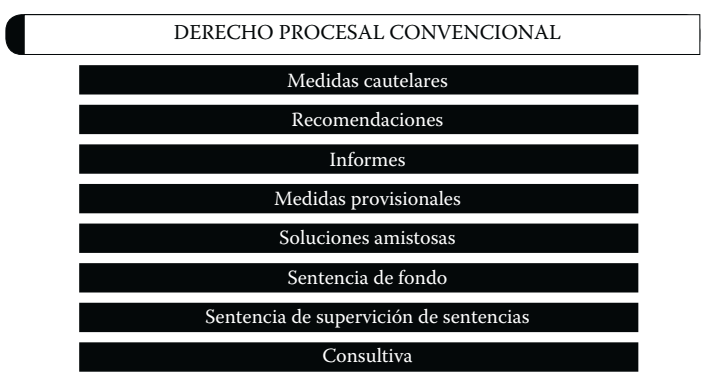

ISSN 2346 - 3473 • pp. 167-197 • Julio - Diciembre de 2015 • Bogotá, D.C. - Colombia 187
4.2 LOS SISTEMAS REGIONALES DE PROTECCIÓN DE DERECHOS HUMANOS UNIVERSALIZACIÓN DEL DERECHO PROCESAL CONVENCIONAL.

Hay tres sistemas jurisdiccionales regionales de protección de derechos humanos, en orden de creación: el europeo 1950 (Pacto de Roma), con el Tribunal Europeo de Derechos Humanos con sede en Estrasburgo, Francia; el Interamericano o latinoamericano ${ }^{38}$ de Derechos Humanos; y el Africano en 1981 (Carta de Banjul), con la Comisión Africana de Derechos Humanos de los Pueblos, el Tribuna Africano de Derechos Humanos y la Corte Africana de Derechos Humanos de los Pueblos, estos últimos fusionados en el año 2004. En este punto, y a forma de corolario, afirmamos que la expansión del Derecho Procesal Convencional se materializa con el fortalecimiento y universalización de los sistemas regionales de protección de Derechos Humanos, a partir de los cuales podemos describir el estado actual de los mismos, sus actuales competencias y los Estados parte que hacen parte del reconocimiento del Derecho Convencional.

\section{2.1 Europa.}

El Sistema Europeo de Derechos Humanos se constituye a partir del Convenio para la protección de los derechos humanos y de las libertades, conocido también como Convención Europea de Derechos Humanos (CEDH), suscrito el 4 de noviembre de 1950 en Roma, “(...) se abrió a la firma y entró en vigor el 3 de septiembre de 1953, tras ser ratificado por diez Estados (...) el Convenio no protege los derechos humanos en general, sino tan solo algunos de los derechos enunciados en la Declaración Universal" ${ }^{\prime \prime}$.

La CEDH prevé una serie de derechos humanos sustantivos en sus primero 18 artículos: la vida, prohibición de la tortura, del trabajo forzado y de la esclavitud, a la libertad y a la seguridad, a un proceso equitativo, libertades de expresión, pensamiento, conciencia, religión, entre otros ${ }^{40}$.

El Tribunal Europeo de Derechos Humanos tiene su fundamento en el artículo 19 de la CEDH que establece que "con el fin de asegurar el respeto de

Acepción propia de los autores debido a que Estado Unidos de Norteamérica y Canadá que conforman la parte norte del continente no tienen aceptada la jurisdicción de la Corte IDH.

39 CUCARELLA GALIANA, Luis-Andrés, "Recursos y procesos para la protección de los derechos humanos en el ámbito europeo", Sistemas regionales de protección de derecho humanos, editorial Revista Jurídica Primera Instancia, Tuxtla Gutiérrez, 2014, pp. 50-51. 40 Ibíd., pp. 53-64.

188 Revista del Instituto Colombiano de Derecho Procesal • No. 42
ALFONSO JAIME MARTÍNEZ LAZCANO Y JAIME ALFONSO CUBIDES CÁRDENAS

los compromisos que resultan para las Altas Partes Contratantes del presente Convenio y sus protocolos, se instituye un Tribunal que funcionará de manera permanente".

Desde que la Corte abrió sus puertas en 1959, los Estados miembros del Consejo de Europa han adoptado una serie de protocolos de la Convención Europea de Derechos Humanos con el objetivo de mejorar y fortalecer su mecanismo de supervisión. En 1998 el Protocolo número 11 sustituye así la estructura de dos niveles iniciales que comprendían la Corte y la Comisión de Derechos Humanos y que se reunían unos pocos días al mes por un único tribunal de tiempo completo. Este cambio puso fin a la función de filtrado de la comisión, lo que permite a los solicitantes presentar sus casos directamente ante la Corte ${ }^{41}$.

El tribunal tiene competencia para conocer todos los asuntos relativos a la interpretación y la aplicación del CEDH y de sus protocolos. Este se compone por 47 Jueces, igual al número de las Altas Partes Contratantes (Estados). Son elegidos por la Asamblea Parlamentaria en razón de cada Alta Parte Contratante, por mayoría absoluta de votos, de una lista de tres candidatos presentada por esa Alta Parte Contratante, para un período de seis años y pueden ser reelegidos. El mandato de los jueces finalizará cuando alcancen la edad de setenta años. Un juez solo podrá ser relevado de sus funciones si los demás jueces deciden, por mayoría de dos tercios, que ha dejado de reunir las condiciones requeridas para serlo.

El Tribunal Europeo tiene dos funciones, jurisdiccional y consultiva. Son cuarenta y siete Estados los que aceptan la jurisdicción del tribunal, entre ellos: Alemania, Austria, Bélgica, Bulgaria, Chipre, Croacia, Dinamarca, Eslovenia, Estonia, Finlandia, Francia, Grecia, Holanda, Hungría, Irlanda, Italia, Letonia, Lituania, Luxemburgo, Malta, Polonia, Portugal, Reino Unido, República Checa, República Eslovaca, Rumanía, Suecia.

\section{2.2 América.}

El Sistema Interamericano de Derechos Humanos ${ }^{42}$ (SIDH), tal como actualmente se integra, tiene su fundamento en la Convención Americana de Derechos Humanos (Convención ADH) o Pacto de San José (Costa Rica), suscrito el 22 de noviembre de 1969 y vigente a partir del 18 de julio de 1978.

\footnotetext{
http://www.echr.coe.int/Pages/home.aspx?p=home [Consultado 15 de marzo de 2015]. MARTíNEZ LAZCANO, Alfonso Jaime. "Sistema Latinoamericano de Protección de Derechos Humanos. Sistemas regionales de protección de derechos humanos. Tuxtla Derechos Humanos. Sistemas regionales de protección de derechos hum
Gutiérrez: Editorial Revista Jurídica Primera Instancia, 2014. pp. 107 y ss.
}

La Convención $\mathrm{ADH}$ está integrada por 82 artículos que prevén los derechos humanos básicos del SIDH, los compromisos de los Estados Parte y la estructura facultades y responsabilidades de la Comisión Interamericana de Derechos Humanos y de la Corte IDH, así como la sustanciación de los procedimientos ante estas instancias.

No todos los miembros de la Organización de los Estados Americanos (OEA) han ratificado la Convención $\mathrm{ADH}$ y no todos reconocen la jurisdicción de la Corte IDH. Veinticuatro son los países que admiten como fuente de derecho nacional a la Convención ADH, a saber: Argentina, Barbados, Bolivia Brasil, Colombia, Costa Rica, Chile, Dominica, Ecuador, El Salvador, Granada Guatemala, Haití, Honduras, Jamaica, México, Nicaragua, Panamá, Paraguay, Perú, República Dominicana, Suriname, Uruguay y Venezuela, que representan el 68\% del total de los países de América.

La Corte IDH quedó integrada el 22 de mayo de 1979, al termino de tres décadas de esfuerzos y proyectos. La Asamblea General de la OEA eligió, durante su Séptimo Período Extraordinario de Sesiones, a los primeros jueces que la compondrían: tres centroamericanos, dos suramericanos, un caribeño $y$ un estadounidense ${ }^{43}$.

La CorteIDH tienejurisdicción sobre todos los casos y controversias sometidas a su conocimiento, sobre la interpretación y aplicación de la Convención IDH y demás instrumentos pertinentes de derechos humanos ratificados por los Estados partes.

La instalación de la Corte IDH se hizo el 3 de septiembre de 1979, en solemne ceremonia desarrollada en el Teatro de la República de San José, Costa Rica sede de la propia Corte Interamericana, bajo convenio entre Costa Rica y la Corte Interamericana, suscrito el 10 de septiembre de $1981^{44}$

La Corte IDH se compone de siete jueces nacionales de los Estados miembros de la OEA, elegidos a título personal entre juristas de la más alta autoridad moral de reconocida competencia en materia de derechos humanos. Deben reunir condiciones requeridas para el ejercicio de sus elevadas funciones judiciales, conforme a la ley del país del cual sean nacionales o del Estado que los proponga como candidatos.

La Corte IDH no puede ser integrada por jueces de la misma nacionalidad, deben ser elegidos por seis años y solo podrán ser reelegidos una vez.

El presidente y el vicepresidente son elegidos por los jueces de la Corte IDH, para un período de dos años y pueden ser reelectos. La elección tendrá lugar en

GARCÍA RAMÍREZ, Sergio, "La Corte Interamericana de Derechos Humanos". México Porrúa, 2011. p. 107.

${ }_{44}$ Ibídem.

190 Revista del Instituto Colombiano de Derecho Procesal • No. 42 
el último período ordinario de sesiones que celebre la Corte IDH el año anterior El período comienza el primer día de la primera sesión del año correspondiente (Convención ADH aa. 52 y 54, RCTIDH a. 3).

La Corte IDH tiene dos funciones esenciales: la consultiva y la contenciosa, como lo determina el artículo $2^{\circ}$ del Estatuto de Corte sobre Competencia y Funciones: "La Corte ejerce función jurisdiccional y consultiva: 1 . Su función jurisdiccional se rige por las disposiciones de los artículos 61,62 y 63 de la Convención. 2. Su función consultiva se rige por las disposiciones del artículo 64 de la Convención".

Son diecinueve los Estados que han reconocido la competencia contenciosa de la Corte IDH: Argentina, Barbados, Bolivia, Brasil, Chile, Colombia, Costa Rica, Ecuador, El Salvador, Guatemala, Honduras, México, Nicaragua, Panamá, Paraguay, Perú, República Dominicana, Suriname y Uruguay, número que equivale al $54 \%$ del total de los países de América.

\subsection{3 África}

El Sistema Africano de los Derechos Humanos y de los Pueblos ${ }^{45}$ se constituyó por medio de la Carta Africana de Derechos Humanos y de los Pueblos o 'Carta de Banjul' aceptada el 27 de junio de 1981, que entró en vigor el 21 de octubre de 1986 .

El artículo $1^{\circ}$ del Protocolo a la 'Carta de Banjul' establece la Corte Africana de Derechos Humanos y de los Pueblos, aprobado por los Estados miembros de la entonces Organización de la Unidad Africana (OUA) en Ouagadougou, Burkina Faso, en junio de 1998. El Protocolo entró en vigor el 25 de enero de 2004 después de su ratificación por parte de más de 15 países del continente africano.

El tribunal tiene jurisdicción sobre todos los casos y controversias sometidas a su conocimiento sobre la interpretación y aplicación de la Carta de Banjul, el Protocolo y otros instrumentos pertinentes de derechos humanos ratificados por los Estados parte.

La Corte inició oficialmente sus funciones en Addis Abeba, Etiopía, en noviembre de 2006, pero en agosto de 2007 trasladó su sede a Arusha, República Unida de Tanzania, donde el Gobierno la ha dotado de instalaciones provisionales en espera de la construcción de una estructura permanente.

\footnotetext{
Cfr. FIGUEIRA TONETTO, Fernanda y LOPES SALDANHA, Jania Maria, "Sistema Africano de los Derechos Humanos y de los Pueblos". Sistemas regionales de protección de derechos humanos. Tuxtla Gutiérrez: Editorial Revista Jurídica Primera Instancia, 2014. pp. 184 y ss.

ISSN 2346 - 3473 • pp. 167-197 • Julio - Diciembre de 2015 • Bogotá, D.C. - Colombia
}

ALFONSO JAIME MARTÍNEZ LAZCANO Y JAIME ALFONSO CUBIDES CÁRDENAS

grupos de personas y derechos. Sin duda, algunos de los factores de esta nueva concepción son la amplitud, movilidad y crecimiento de las fuentes que pueden ser consideradas integrales y aplicables a los Estados parte que reconozcan y acepten las jurisdicciones supranacionales.

La discusión del Derecho Procesal Convencional no encuentra mucha resistencia dentro de su dimensión originaria, debido a su naturaleza internacional, el problema o el debate se centra dentro de la recepción nacional que deben hacer los Estados de los derechos humanos sustantivos convencionales, sus nuevos escenarios de aplicación y los problemas o las confrontaciones normativas dentro de las leyes internas y las ordenes o decisiones de los órganos supranacionales.

El Derecho Procesal Convencional no es una subcategoría del Derecho Procesal Constitucional, debido a que está conformada por mecanismos jurisdiccionales internacionales diferentes con estatuto, normatividad y reglamentación diferente a la nacional y dotada de una jurisdicción supranacional con relación congruente con los ordenamientos nacionales. La diversidad de medios jurisdiccionales o cuasi jurisdiccionales que adopten los Estados que tengan como intención anular los actos de cualquier autoridad que sean contrarios a os mandatos de la constitución o que provoquen una determinada conducta pública, cuyas motivaciones sean fundamentadas bajo el principio de supremacía constitucional (argumento de autoridad) integrando el derecho procesal constitucional, en contraste el derecho procesal convencional de derechos humanos se rige bajo el principio pro homine (argumento de contenidos)

El paradigma constitucional consolidado dentro del derecho procesal constitucional, ejecutado y acrecentado por las constituciones, las acciones o mecanismos constitucionales y los tribunales constitucionales, debe abrir paso a la inclusión del Derecho Procesal Convencional, para propiciar el cambio hacia un paradigma convencional, por eso, no resulta absurdo decir que pueden existir constituciones inconvencionales. La Corte IDH, en este punto nos ha dejado tres ejemplos que vale la pena conocer, examinar y discutir, por las implicaciones que tuvieron para los Estados de Chile y México. La utilización del llamado bloque de constitucionalidad determinado por las normas que están al mismo nivel de la Constitución, se fortalece con la aparición del Derecho Convencional, este no busca desplazar su condición de amplificador de los ordenamientos jurídicos, sino, todo lo contrario, dotarlo de más elementos normativos.

Para una mayor comprensión del derecho convencional de los derechos humanos, este debe diferenciarse en dos perspectivas, desde el punto de vista sustantivo y procesal, esto se debe a que desde la primera óptica se establecen los derechos materiales que tiene toda persona y que le fueron otorgados no solo por los instrumentos regionales sino también los universales
El tribunal está integrado por once jueces, nacionales de los Estados miembros de la Unión Africana. Los primeros jueces del tribunal fueron elegidos en enero de 2006, en Jartum, Sudán. Ellos prestaron juramento ante la Asamblea de Jefes de Estado y de Gobierno de la Unión Africana, el 2 de julio de 2006, en Banjul, Gambia. Los jueces de la Corte son elegidos, después de la nominación por sus respectivos Estados, a título personal entre juristas africanos de probada integridad, de reconocida competencia práctica, judicial o académica y experiencia en el campo de los derechos humanos. Los jueces son elegidos para un período de cuatro o de seis años, una vez le sea renovado el período. Los jueces de la Corte elegirán un presidente y vicepresidente de la misma Corte para un período de dos años. Pueden ser reelegidos por una sola vez. El Presidente de la Corte reside y trabaja de tiempo completo en la sede de la Corte, mientras que los otros diez jueces laboran de tiempo parcial. En el cumplimiento de sus funciones, el presidente es asistido por un secretario, que realiza funciones administrativas y de gestión de la Corte.

En concreto, la Corte tiene dos tipos de funciones: contenciosa y consultiva. Tiene jurisdicción sobre todos los casos y controversias que se le presenten en relación con la interpretación y aplicación de la 'Carta de Banjul', el Protocolo de la Corte y otros instrumentos pertinentes de derechos humanos, ratificados por los Estados parte.

A la fecha, solo los siguientes veintiséis Estados, de los cincuenta y cuatro que conforman el continente africano, han ratificado el Protocolo: Argelia, Burkin Faso, Burundi, Costa de Marfil, Comoras, Congo, Gabón, Gambia, Ghana, Kenia Libia, Lesotho, Malí, Malawi, Mozambique, Mauritania, Mauricio, Nigeria, Níger, Ruanda, Sudáfrica, Senegal, Tanzania, Togo, Túnez y Uganda.

\section{CONCLUSIONES.}

El presente estudio surge de la necesidad de conceptualizar con una visión propositiva al Derecho Procesal convencional de los Derechos Humanos desde un escenario académico e investigativo, a través de este se busca subsanar una zanja realizada por varios textos que utilizan el concepto sin dotarlo de contenido y los correctos elementos para su definición como ciencia autónoma e independiente del Derecho Procesal Constitucional.

Uno de los mecanismos que ha habilitado el Derecho Procesal Convencional dentro de la esfera interamericana es el corpus iuris latinoamericano, compuesto no solo por normas convencionales o regionales, sino por elementos normativos del sistema universal de protección de Derechos Humanos. Los tratados que hacen parte del SIDH son reconocidos expresamente por la jurisprudencia de la Corte IDH, actualmente son $29 \mathrm{y}$ en ellos se protegen diferentes situaciones,

192 Revista del Instituto Colombinno de Derecho Procest $\cdot$ No. 42

Los sistemas de protección regionales de derechos humanos funcionan como examinadores de los actos u omisiones, incluyendo las normas constitucionales de los Estados parte, que vulneren los derechos humanos convencionales. Pues ninguno de los Estados que haya ratificado la convención y esté sujeto al SIDH puede tomar disposiciones internas para no aplicar efectivamente los parámetros internacionales, que generan verdaderas inconvencionalidades, por estar en incompatibilidad con los estándares internacionales.

Se afirma categóricamente que para que surja el Derecho Procesa Convencional, se debe contar con una jurisdicción internacional, unas fuente propias, dinámicas e incluyentes de otros sistemas y unos jueces que cumplan funciones tanto jurisdiccionales como consultivas. No debe entenderse su aplicabilidad como excluyente porque dentro de la órbita nacional se regirá bajos los parámetros del Derecho Procesal Constitucional y, en lo internacional, por la novel ciencia. La importancia de su independencia procesal es necesaria y elemental si se quiere abordar de manera científica su rediseño.

El Derecho Procesal Convencional de los Derechos Humanos es un instrumento de regularidad que impacta en todo norma sin importar la jerarquía de esta y que funciona más de forma invasiva que complementaria. Este, a su vez, crea parámetros o estándares de validez internacional para la mejor garantía y protección efectiva de los derechos de las personas.

Sería muy pretencioso determinar que la discusión sobre el Derecho Procesal Convencional se agota dentro de este escrito, este solo es aporte para la discusión sobre los nuevos contextos que deberán ser abordados por la comunidad científica; para el caso colombiano, en la relación de las jurisdicciones supranacionales en la eventualidad de un acuerdo de paz y su verificación a la luz de estándare jurisprudenciales, además de la compartida situación con México en la revisión de nuevos casos que vinculen crímenes de lesa humanidad por agentes de Estado. Las tensiones se seguirán presentando y los aportes vendrán de constitucione convencionalizadas, de lo que se ha llamado interpretación conforme y el apego por parte de los Estados de la Doctrina del Margen de Apreciación Nacional para a restricción de derechos dentro de sus orbitas internas.

\section{REFERENCIAS.}

AGUILAR, Gonzalo. "La internacionalización del Derecho Constitucional". Estudios Constitucionales. Año 5. Vol. 1. Talca: Universidad de Talca, 2007. pp. 223-281.

ARTEAGA NAVA, Elisur. Tratado de derecho constitucional. Volumen 1. México: OXFORD, 2003

AYALA, Carlos M. "Recepción de la jurisprudencia internacional sobre los derechos humanos por la jurisprudencia constitucional". Derecho procesal constitucional. México: Porrúa, 2004. pp. 1471-1472 
AYALA, Carlos. "Recepción de la jurisprudencia internacional sobre Derechos Humanos por la jurisprudencia constitucional". Revista Urbe Et Ius. Vol. 1 № 11. Lavalle: Asociación Civil Urbe et Ius, 2014. pp. 57-83.

BARRAGÁN BARRAGÁN, José. "Constitución”. Diccionario Jurídico Mexicano. Tomo I, Instituto de Investigaciones jurídicas UNAM, 5a ed. México: Porrúa, 1992.

BAZÁN, Víctor (Coordinador). Derecho procesal constitucional americano y europeo. 2 tomos. Primera Edición. Buenos Aires: Editorial Abeledo Perrot, 2010. p. 1836.

BERINZONCE, Roberto Omar. "El principio de legalidad formal bajo el prisma de la Constitución "normatizada", Revista del Instituto Colombiano de Derecho Procesal. Edición virtual número 40. Bogotá, 2014.

CARPIZO, Enrique. "El control de convencionalidad y su relación .con el sistema constitucional mexicano. Hacia una simple actividad protectora de los derechos humanos" Boletín Mexicano de Derecho Comparado. núm. 138, 2013, México: UNAM. p. 959.

CARRASCO SOULÉ, Hugo. "El derecho sustantivo del Sistema Interamericano de derecho humanos". Temas Selectos del Sistema Interamericano de Protección de Derechos Humanos. Tuxtla Gutiérrez: Editorial Revista Jurídica Primera Instancia, 2012.

COLOMBO CAMPBELL, Juan. “La justicia constitucional”. Revista de Derecho (Valdivia), jul. 2003, vol. 14. p. 259-284.

CUBIDES, Jaime. "La relación del fenómeno de la constitucionalización del derecho con el derecho procesal constitucional". Revista Justicia Juris. Vol. 8. № 1. 2012. Bogotá: Universidad Autónoma del Caribe. pp. 22-29.

-.--.-. "Disertaciones sobre las parejas del mismo sexo a través del rol ejercido por la Corte Constitucional Colombiana en el reconocimiento de sus derechos". Anuario de Derecho. Año 28. № 28. 2011. Mérida: Universidad de los Andes. pp. 13-36.

D’EMPEIRE, Eduardo Alfredo “Las Garantías Judiciales: un análisis de estándares fijados 2013. p. 162 DÍAZ REVORIO, Francisco. “El control de constitucionalidad de las omisiones legislativas
relativas en el derecho comparado europeo". Revista Española de Derecho Constitucional. relativas en el derecho comparado

ESPINOSA SALDAÑA, Eloy. "Sentencias interpretativas: Sus alcances y algunas eflexiones sobre su uso a la luz de la experiencia peruana". Estudios Constitucionales. vol.4, núm. 2, 2006. pp. 203-220.

EYNER ISAZA, Henry. Los Derechos Humanos y Sistema Interamericano. Bogotá: Ediciones Nueva Jurídica, 2014.

FERRER MAC-GREGOR, Eduardo (Coordinador), Derecho Procesal Constitucional. 4 ed. México: Porrúa, 2003.

...-...-. "La ciencia del derecho procesal constitucional" Díkaion. Año 22, núm., 17, 2008. pp. $97-129$.

-..-.--- Panorámica del Derecho Procesal Constitucional y Convencional. Madrid: Editorial Marcial Pons, 2013.

-..-.-.-Justicia local constitucional. La nueva sala constitucional en el estado de Veracruz. México: Ed., Fundación Universitaria de Derecho, Administración y Política SC, 2003.

ISSN 2346 - 3473 • pp. 167-197 • Julio - Diciembre de 2015 • Bogotá, D.C. - Colombia

ALFONSO JAIME MARTíNEZ LAZCANO Y JAIME ALFONSO CUBIDES CÁRDENAS

TURÉGANO, Isabel. “Soberanía”. Eunomía: Revista en Cultura de la Legalidad. №. 4. Madrid: Universidad Carlos III, 2013. pp. 154-162.

VELANDIA CANOSA, Eduardo Andrés (Coordinador). Estudios de Derecho Procesal Constitucional. Tomo II. Bogotá: Editores Ltda., 2011.

.....-.- "Derecho procesal constitucional transnacional. El proceso ante la Corte Interamericana de Derechos Humanos". Neoprocesalismo. Villahermosa: Universidad Juárez Autónoma de Tabasco, 2014. p. 400

VILLALBA BERNIÉ, Pablo Darío. Sistema Interamericano de Derechos Humanos. Asunción: La Ley, 2014

\section{JURISPRUDENCIA}

CORTE CONSTITUCIONAL DE COLOMBIA. Sentencia T-525 de 1997 CORTE CONSTITUCIONAL DE COLOMBIA. Sentencia SU-559 de 1997. CORTE CONSTITUCIONAL DE COLOMBIA. Sentencia T-068 de 1998, CORTE CONSTITUCIONAL DE COLOMBIA. Sentencia T-153 de 1998 CORTE CONSTITUCIONAL DE COLOMBIA. Sentencia T-590 de 1998 CORTE CONSTITUCIONAL DE COLOMBIA. Sentencia T-606 de 1998 CORTE CONSTITUCIONAL DE COLOMBIA. Sentencia T-607 de 1998 CORTE CONSTITUCIONAL DE COLOMBIA. Sentencia SU-250 de 1999 CORTE CONSTITUCIONAL DE COLOMBIA. Sentencia T-847 de 2000 CORTE CONSTITUCIONAL DE COLOMBIA. Sentencia T-966 de 2000 CORTE CONSTITUCIONAL DE COLOMBIA. Sentencia T-025 de 2004. CORTE CONSTITUCIONAL DE COLOMBIA. Sentencia SU-090 de 2008. CORTE CONSTITUCIONAL DE COLOMBIA. Sentencia T-057 de 2015. CORTE IDH. Caso Goiburú y otros Vs. Paraguay. Fondo, reparaciones y costas. Sentencia de 22 de septiembre de 2006. Serie C No. 153, Pár. 85.

CORTE IDH. Caso Gomes Lund y otros (Guerrilha do Araguaia) Vs. Brasil. Excepciones preliminares, fondo, reparaciones y costas. Sentencia de 24 de noviembre de 2010. Serie C No. 219, Pár. 111.

CORTE IDH. Caso Anzualdo Castro Vs. Perú. Excepción preliminar, fondo, reparaciones y costas. Sentencia de 22 de septiembre de 2009. Serie C No. 202, Pár. 67.

CORTE IDH. Caso Forneron e hija Vs. Argentina. Fondo, reparaciones y costas. Sentencia de 27 de abril de 2012 Serie C No. 242, Pár. 137; Corte IDH. Caso de los "Niños de la Calle" (Villagrán Morales y otros) Vs. Guatemala. Fondo. Sentencia de 19 de noviembre de 1999. Serie C No. 63, Pár. 194

CORTE IDH. Caso Ríos y otros Vs. Venezuela. Excepciones preliminares, fondo, reparaciones y costas. Sentencia de 28 de enero de 2009. Serie C No. 194, Pár. 277.
-.-- Los tribunales constitucionales en Iberoamérica. México: FUNDA (Fundación Universitaria de Derecho, Administración y Política, S.C.), 2002.

FIX ZAMUDIO, Héctor, "El Derecho Procesal Constitucional como un sector de la Defensa de la Constitución". Estudios de Derecho Procesal Constitucional. Tomo Bogotá: Il. Editores Ltda., 2011. p. 165.

GARCÍA RAMíREZ, Sergio. La Corte Interamericana de Derechos Humanos. México: Porrúa, 2011.

GONZÁLEZ VALENZUELA, Alejandro. "El derecho procesal constitucional transnacional". Revista de la Facultad de Derecho. $\mathrm{N}^{\circ}$ 64, 2009. pp. 243-297.

GORDILLO PÉREZ, Luis Ignacio. "Hacia la consolidación de un constitucionalism interordinamental". Anuario iberoamericano de justicia constitucional. №. 18, 2014. pp. 275-328.

GUASTINI, Ricardo. La "constitucionalización" del ordenamiento jurídico: el caso italiano. Estudios de Teoría Constitucional. Primera Edición. México: UNAM, IIJ, 2001. pp. i-273.

ISLAS COLÍN, Alfredo y MARTÍNEZ LAZCANO, Alfonso Jaime (Coordinadores). Neoprocesalismo. Villahermosa: Universidad Juárez Autónoma de Tabasco, 2014 LAMA MORE, Héctor. "Sentencias del Tribunal Constitucional. Tipología. Sentencias interpretativas". Diálogo con la Jurisprudencia. Año 11, núm. 84, 2005. pp. 19-34.

MARTÍNEZ LAZCANO, Alfonso Jaime (Coordinador). Sistemas Regionales de Protección de Derechos de Humanos. Tuxtla Gutiérrez: Editorial Revista Primera Instancia, 2014

------- Temas Selectos del Sistema Interamericano de Protección de Derechos Humanos. Tuxtla Gutiérrez: Editorial Revista Jurídica Primera Instancia, 2012.

MIRANDA CAMARENA, Adrián Joaquín y NAVARRO RODRÍGUEZ, Pedro. "E principio de interpretación conforme en el derecho constitucional mexicano". Opinión Jurídica. 13, 2014. pp. 69-79.

MORENO ALFONSO, René, "El valor de la jurisprudencia de los tribunales internacionales en el derecho local". Temas Selectos del Sistema Interamericano de Protección de Derechos Humanos. Tuxtla Gutiérrez: Editorial Revista Jurídica Primera Instancia, 2012. p. 337.

MORA, Jorge. "El Control De Convencionalidad: Un Replanteamiento de principio y fuentes del Derecho". Revista Republicana. № 12. Bogotá: Corporación Universitaria Republicana, 2012. pp. 217-237.

NOGUEIRA ALCALÁ, Humberto. "Los desafíos del control de convencionalidad del corpus iuris interamericano para las jurisdicciones nacionales". Boletín Mexicano de Derecho Comparado. núm. 135, XLV, 2012. pp. 1167-1220.

OLIVECRONA, Karl. Lenguaje Jurídico y Realidad. México: Editorial Fontamara, 2010.

RODRÍGUEZ MANZO Graciela, et al. Bloque de Constitucionalidad en México. Suprema Corte de Justicia de la Nación México, 2013.

SAGÜES, Néstor Pedro. Derecho Procesal Constitucional Logros y Obstáculos. Lima Centro de Estudios Constitucionales, 2008.

SAÍD, Alberto y GONZÁLEZ GUTIÉRREZ Isidro M. Teoría General del Proceso. México: IURE editores, 2006. p. 100. 